\title{
Effect of trace magnesium addition on the characteristics of mechanical properties in high strength low alloy steel
}

\author{
LV Ming $^{1}$, LI Xiaobing ${ }^{1,}{ }^{*}$, Min Yi ${ }^{1}$, LIU Chengjun ${ }^{1}$, JIANG Maofa ${ }^{1}$, WANG Bo ${ }^{2}$ \\ and WANG Xiaopu ${ }^{2}$
}

${ }^{1}$ Key Laboratory for Ecological Metallurgy of Multimetallic Mineral (Ministry of Education), School of Materials and Metallurgy, Northeastern University, Shenyang, 110819, P. R.China

${ }^{2}$ Research Institute of Shandong Iron \& Steel Group Co., Ltd. 250101, P. R. China

${ }^{*}$ Corresponding Author: LI Xiaobing; E-mail: lixb_neu@sina.com

Keywords: High strength low alloy steel; magnesium; mechanical properties; microstructure Abstract: In order to reveal the function of $\mathrm{Mg}$ on the characteristics of mechanical properties in high strength low alloy steel, the steels containing with different $\mathrm{Mg}$ contents were refined with vacuum induction furnace and rolled with double-stick reversible rolling mill. The characteristics of mechanical properties and rolled microstructure were systematically investigated in present study. The results show that, the yield and the tensile strengths increase with $\mathrm{Mg}$ content from $0.0008 \%$ to $0.0026 \%$. The $0.0026 \% \mathrm{Mg}$ addition makes the yield strength, tensile strength, and elongation of steel increase to $473 \mathrm{MPa}, 605 \mathrm{MPa}$ and $36.5 \%$, increasing by $38 \mathrm{MPa}, 70 \mathrm{MPa}$, and $8 \%$ compared with the steel without $\mathrm{Mg}$ addition. The improved toughness is obtained both the transversal and longitudinal impact, and the increment in the Charpy impact toughness is also characterized to increase with the concentrations from $0.0008 \%$ to $0.0026 \%$. The improved toughness and tensile of $\mathrm{Mg}$-containing steels are attributed to both the refined microstructure and the bainite dominated microstructure in steel. Moreover, the bainitic structure obtained by the addition of $\mathrm{Mg}$ into the molten steel results in a continuous yield behavior emerges in $0.0026 \% \mathrm{Mg}$ steel.

\section{Introduction}

Magnesium is an alkaline earth metal element with strong affinity with oxygen, sufur, phosphorus, etc. in steel, which attracts many metallurgists to pay close attentions on its function in the steel. In early stage, the studies on magnesium were mainly focusing on steelmaking process, especially focusing on the modification of inclusions, including size, chemical composition and morphology. Fu et al. [1] found that $0.003 \% \mathrm{Mg}$ treatment in Al-killed steel can effectively modify $\mathrm{Al}_{2} \mathrm{O}_{3}$ into dispersed fine $\mathrm{MgO}$ inclusions, and replace the elongated $\mathrm{MnS}$ inclusions with small $\mathrm{MgS} \cdot \mathrm{MgO}, \mathrm{MgS} \cdot \mathrm{MnS} \cdot \mathrm{MgO}$ complex inclusions. Kim et al.[2] reported that $\mathrm{Ti} / \mathrm{Mg}$ deoxidized can even further reduce the size of inclusions from $2.1 \mu \mathrm{m}$ to $1.2 \mu \mathrm{m}$ compared single $\mathrm{Mg}$ deoxidized in the low carbon steels. It was therefore concluded that trace $\mathrm{Mg}$ was good for the refinement of inclusions. Through in-situ observation experiments with a confocal scanning laser microscope, Kimura et al.[3] have measured the attractive force between a pair of inclusions such as alumina-magnesia complex inclusions, magnesia and alumina inclusions, and their studies shown that the attractive force between a pair of inclusions, for alumina-magnesia complex inclusions and magnesia, was found to be approximately $10^{-17}$ to $10^{-16} \mathrm{~N}$ and one-tenth of that between a pair of alumina inclusions, which may be a mechanism of Mg-containing inclusions not easily to aggregate in liquid steel.

In addition to the inclusion modifications in steel, Wen et al.[4] have calculated the disregistry between $\mathrm{Mg}$-containing inclusions(mainly including $\mathrm{MgO}, \mathrm{MgAl}_{2} \mathrm{O}_{4}, \mathrm{MgS}$ ) and the ferrite $\mathrm{Fe}$ phase at $1185 \mathrm{~K}$ (austenite to ferrite start temperature) and found these inclusions have small disregistry, especially the values between $\mathrm{MgAl}_{2} \mathrm{O}_{4}, \mathrm{MgO}$ and ferrite Fe. From these results, they concluded that some $\mathrm{Mg}$-containing inclusions may facilitate the heterogeneous nucleation of ferrite during supercooled austenite decomposition resulted in refinement in microstructure. A successful example using the above theory is that the Japanese company Nippon Steel take the advantage of the abundant high melting point $\mathrm{MgO}, \mathrm{MgS}$ and $\mathrm{Mg}(\mathrm{O}, \mathrm{S})$, with sizes as small as $10-100 \mathrm{~nm}$, to prevent the growth of 
austenitic grain and promote the intergranular ferrite nucleation in the process of large heat input welding[5]. Since then the effects of $\mathrm{Mg}$ addition on the microstructure of steel are much more intensively studied. On the other hand, Isobe[6] and Kimura et al. [7] have investigated the $\mathrm{Mg}$ addition on the equi-axed crystallization in the low carbon steel and ferritic stainless steel, respectively, and they concluded that equi-axed solidification was promoted by adding $\mathrm{Mg}$ resulting from heterogeneous nucleation by $\mathrm{MgO}$ or $\mathrm{MgO} \cdot \mathrm{Al}_{2} \mathrm{O}_{3}$. Furthermore, some other studies with regard to the function of $\mathrm{Mg}$ in microstructure are investigated in the improvements of the heat-affected zone (HAZ) microstructure and toughness in low carbon through utilizing the "oxide metallurgy[8]" theory. Chai et al.[9] reported that $\mathrm{Mg}$ addition into Ti-killed steel effectively improved the coarse-grained heat affected zone(CGHAZ) microstructure and impact toughness; they found Ti-Mg-O compound oxides are potent to nucleate an acicular ferrite, and single-phase $\mathrm{MgO}$ is impotent to nucleate an acicular ferrite. Zhu et al.[10] also found that $\mathrm{Mg}$ could evidently increase the ratio of acicular ferrite crystals appearing at large angles boundaries to each other in HAZ of low carbon steels.

Therefore, most of the researches about the function of $\mathrm{Mg}$ in the control of microstructure in steel are mainly focusing on the effects of the as-cast microstructure and the improvement of the heat-affected zone (HAZ) microstructure. By comparison, the function of $\mathrm{Mg}$ addition on the mechanical properties in steel is much less studied. In the present work, the effect of $\mathrm{Mg}$ addition on the mechanical properties in a high strength low alloy steel is systematically investigated.

\section{Experimental procedure}

\section{Sample Preparation}

Three steels were smelting in vacuum induction furnace with the capacity of $30 \mathrm{~kg}$ under the inert $\mathrm{Ar}$ atmosphere. When all alloys melted completely, we kept the inside pressure of furnace at $-0.03 \mathrm{MPa}$ through blowing into the Ar gas, then added Ni-18wt pet $\mathrm{Mg}$ alloy to the liquid steel. After adding $\mathrm{Ni}-\mathrm{Mg}$ alloy the liquid steel was refined for $1 \mathrm{~min}$ and then cast into ingots.

The total concentration of $\mathrm{Mg}$ element in metals was analyzed by using inductively coupled plasma-emission spectrometry(ICP-AES).In addition, the total oxygen and nitrogen contents in metals were analyzed by TC-600 nitrogen oxygen analyzer. The chemical composition of the specimens is shown in Table 1, in which the steel 1 is the benchmark FH40 steel, steel 2 and steel 3 are Mg-added FH40 steels, and the additions of magnesium by using Ni-Mg alloy are respectively 0.024 and $0.072 \mathrm{wt}$ pct.

Table 1 Chemical composition of test steel (wt.pct)

\begin{tabular}{ccccccccccccc}
\hline Steel & $\mathrm{C}$ & $\mathrm{Si}$ & $\mathrm{Mn}$ & $\mathrm{P}$ & $\mathrm{S}$ & $\mathrm{Ni}$ & $\mathrm{Al}$ & $\mathrm{Nb}$ & $\mathrm{Ti}$ & $\mathrm{T} . \mathrm{N}$ & $\mathrm{T} . \mathrm{O}$ & $\mathrm{Mg}$ \\
\hline 1 & 0.052 & 0.23 & 1.53 & 0.009 & 0.003 & 0.29 & 0.028 & 0.040 & 0.014 & 0.0076 & 0.0037 & - \\
2 & 0.046 & 0.21 & 1.51 & 0.008 & 0.005 & 0.29 & 0.031 & 0.042 & 0.014 & 0.0066 & 0.0041 & 0.0008 \\
3 & 0.051 & 0.20 & 1.55 & 0.008 & 0.005 & 0.31 & 0.030 & 0.038 & 0.013 & 00065 & 0.0040 & 0.0026 \\
\hline
\end{tabular}

In order to make the metals micro-structure and composition more homogeneous, the metals were all subjected to forging with reheated temperature about $1150 \sim 1180^{\circ} \mathrm{C}$. The forging samples were rolled into approx. 12-mm plate using Thermo-mechanical Control Processing (TMCP) on the two-high $450 \mathrm{~mm}$ experimental hot reverse rolling mill. The rolling craft of this study is divided into two stages, including primary rolling above the recrystallization temperature $\left(T_{\mathrm{nr}}\right)$ and precision rolling at the range from $A \mathrm{r} 3$ temperature to recrystallization temperature. The recrystallization temperature of tested study was estimated approx. $990^{\circ} \mathrm{C}$ with the following empirical formula[11]. The Ar3 temperature of tested steel was calculated approx. $840^{\circ} \mathrm{C}$ by using thermodynamic software FactSage6.3.

$$
T_{\mathrm{nr}}=887+464 \mathrm{C}+890 \mathrm{Ti}+363 \mathrm{Al}-357 \mathrm{Si}+6445 \mathrm{Nb}-644 \sqrt{\mathrm{Nb}}+732 \mathrm{~V}-230 \sqrt{\mathrm{V}}
$$

Figure 1 shows the process parameters of TMCP. The tested steels were reheated to $1200^{\circ} \mathrm{C}$ and held for more than $2 \mathrm{~h}$, and then subjected to primary rolling at the $50 \%$ deformation within the $1140 \sim 1180^{\circ} \mathrm{C}$ temperature range through three passes. After primary rolling process, the tested were 
also subjected to precision rolling at approx. $880^{\circ} \mathrm{C}$. Considering the large deformation during each pass in the austenitic nonrecrystallization zone is not much too necessary for Nb-containing low alloy steel, instead, the total deformation is more important. Therefore, in the austenitic non-recrystallization zone, the tested steels were all used $70 \%$ deformation during four passes. Finally, the testes steels were followed with a faster cooling rate of $9 \sim 11^{\circ} \mathrm{C} / \mathrm{s}$ during $820 \sim 450{ }^{\circ} \mathrm{C} / \mathrm{s}$ and a final normalizing cooling method after $450^{\circ} \mathrm{C}$.

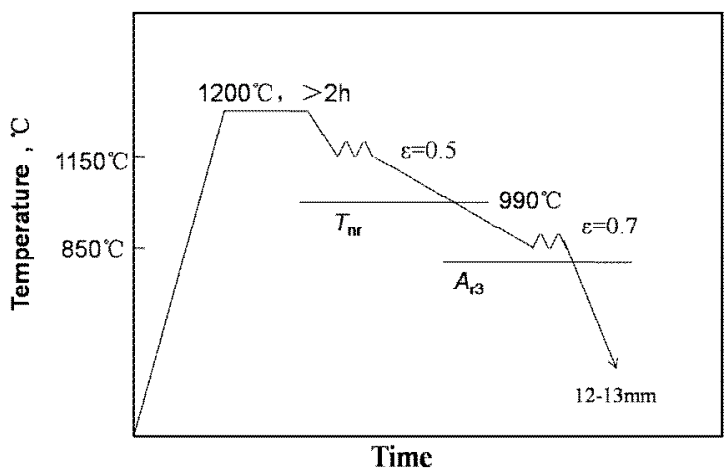

Figure 1 Thermal simulation process of Thermo-mechanical Control Processing

\section{Investigate the Mechanical Properties}

The mechanical properties tests are consisted of Charpy V-notch impact testing and tensile testing. The Charpy $\mathrm{V}$-notch impact testing was conducted on pendulum rebound impact testing machine (SANS ZBC2502-D) at $-40^{\circ} \mathrm{C}$ low temperature, and the notched impact specimens cut from perpendicular and parallel to rolling direction were machined into $10 \times 10 \times 55 \mathrm{~mm}$. The tensile testing was conducted on electronic universal testing machine (SANS CMT5105) at room temperature, and the tensile samples were processed according to $R 7$ standard. The indexes of yield strength $\left(R_{\mathrm{eL}}\right)$, tensile strength $\left(R_{\mathrm{m}}\right)$ and extension $\left(A_{5}\right)$ are discussed in the tensile testing.

\section{Observation of Rolled Microstructure}

For deeply characterizing the microstructure changes in the different magnesium treatment steels, in the present study, the rolled microstructure characteristic were all investigated. Metallographic specimens of dimensions $12 \times 12 \times 10 \mathrm{~mm}$ were respectively cut from rolled plates. All specimens were polished with an automatic grinder polisher under a fixed polishing load. The polished surface of each specimens was slightly etched for $15 \mathrm{~s}$ with $3 \%$ nital solution for the observation of OM (ZEISS-Axio Imager M2m). The average grain size was determined by means of image analysis.

\section{Results and discussion}

\section{Effect of Mg on Tensile and Charpy Impact Properties}

Figure 2 shows the results of tensile tests for the three steels. As can be seen from Fig.2(a), the curves show a similar characteristic of elastic deformation among the steels, while a slice of differences are being in the in the stage of yield, plastic deformation and shrinkage deformation. By comparison, the steel 1 and 2 show a significant yield phenomenon, whereas a continuous yield behavior emerges in steel 3.

From the curves, yield strength $\left(R_{\mathrm{eL}}\right)$, tensile $\operatorname{strength}\left(R_{\mathrm{m}}\right)$, and elongation $\left(A_{5}\right)$ were measured, and the results are summarized in Fig.2(b). It is noted that the Mg-added steels(steel 2 and 3) show higher tensile strength than the steel absence of $\mathrm{Mg}$. The $0.0026 \% \mathrm{Mg}$ addition makes the yield strength, tensile strength, and elongation of steel increase to $473 \mathrm{MPa}, 605 \mathrm{MPa}$ and $36.5 \%$, increasing by $38 \mathrm{MPa}, 70 \mathrm{MPa}$, and $8 \%$ compared with the steel without $\mathrm{Mg}$ addition. 

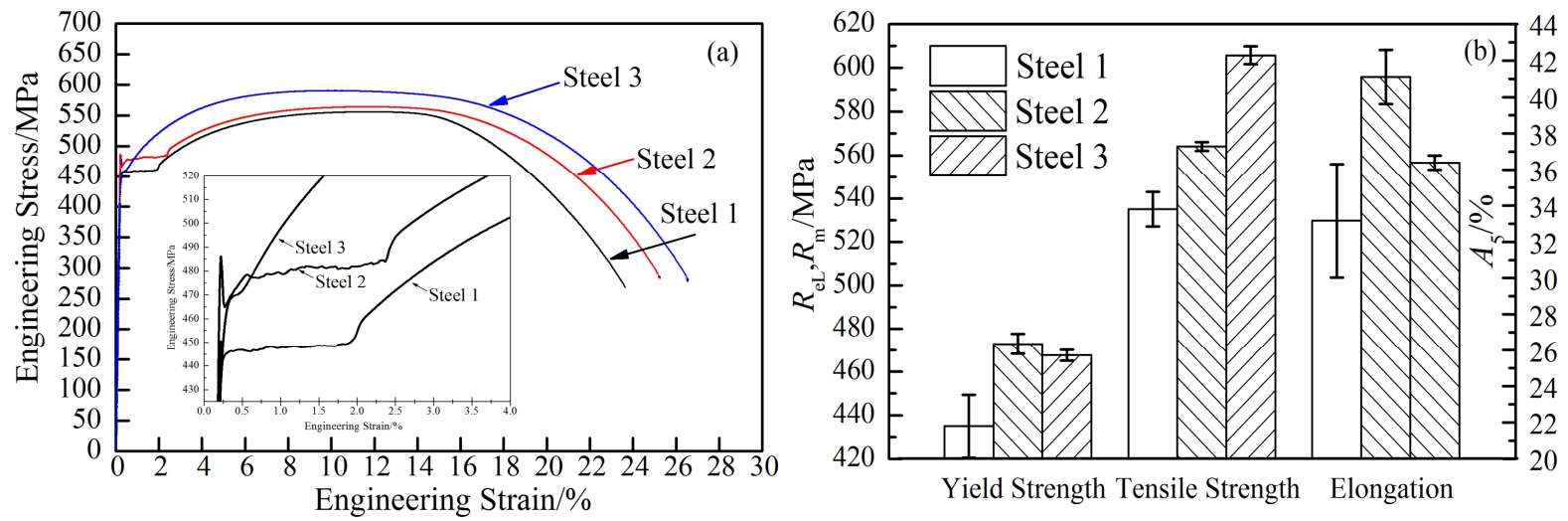

Figure 2 Results of tensile tests, (a) room-temperature tensile stress-strain curves of the steels; (b) mechanical parameters of tension test

Figure 3 presents the transversal and longitudinal impact testing curve of rolling state steels with different magnesium content. From the related curves, it can be seen that a general increase is observed in the impact curves of the Mg-bearing samples which are perpendicular to rolling direction, especially for the steel 3 sample, while the increase tendency is not obvious among the samples which are parallel to rolling direction.

From the curves, the crack propagation energy, plastic energy, and impact energy were measured, and the results are summarized in Figure 4. As can be noted in Fig.4(a), both the crack propagation energy and plastic energy are increased by $\mathrm{Mg}$ addition. Moreover, the impact energy is also promoted by $\mathrm{Mg}$ addition. Furthermore, the increment in the Charpy impact toughness is characterized to increase with the concentrations from $0.0008 \%$ to $0.0026 \%$.
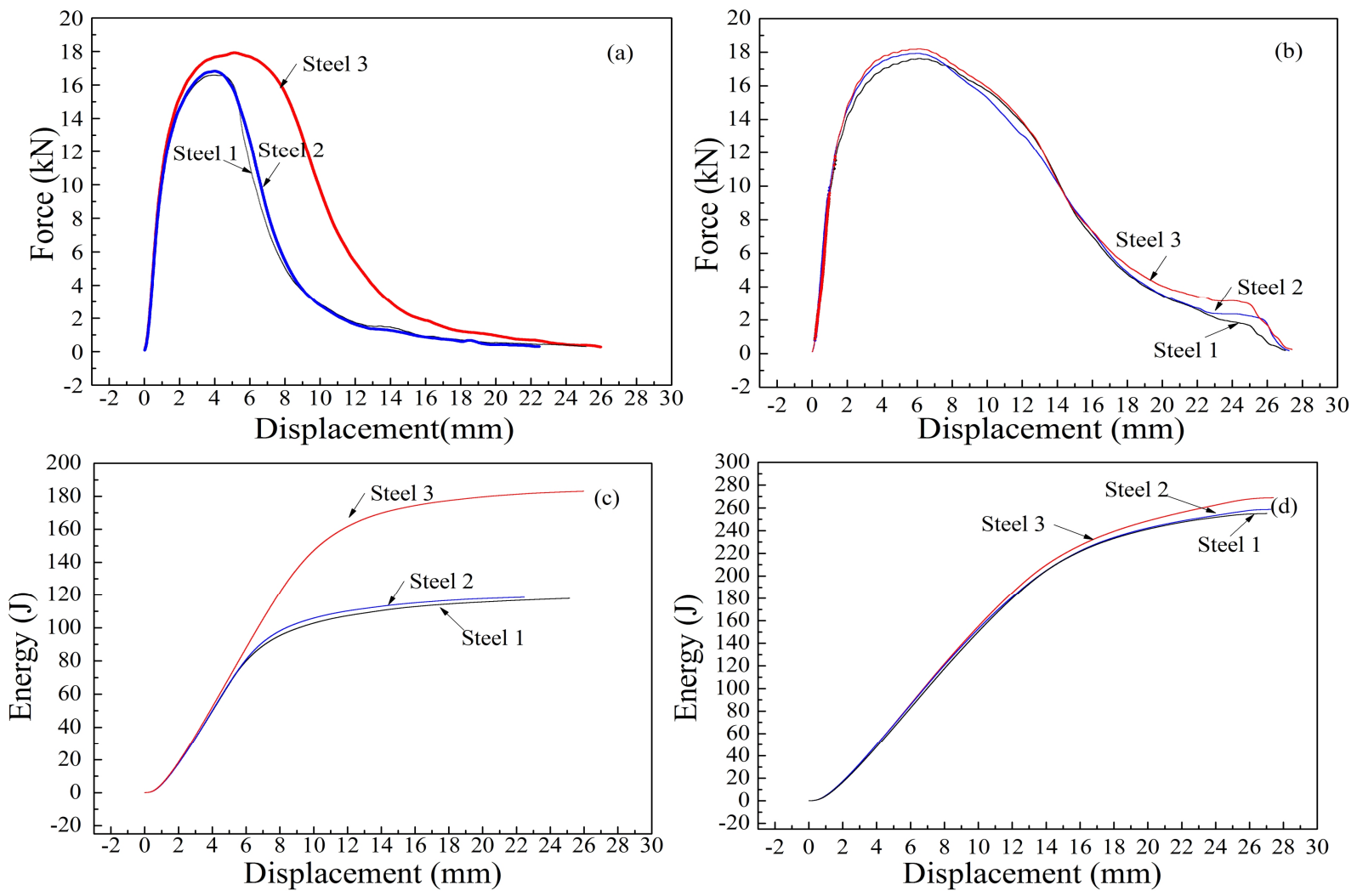

Figure 3 The transversal and longitudinal impact testing curve of rolling state steel with different magnesium content, (a)the relationship between displacement and force on the perpendicular to rolling direction;(b) the relationship between displacement and force on the parallel to rolling direction;(c) the relationship between displacement and impact energy on the perpendicular to rolling direction; (d) the relationship between displacement and impact energy on the parallel to rolling direction 

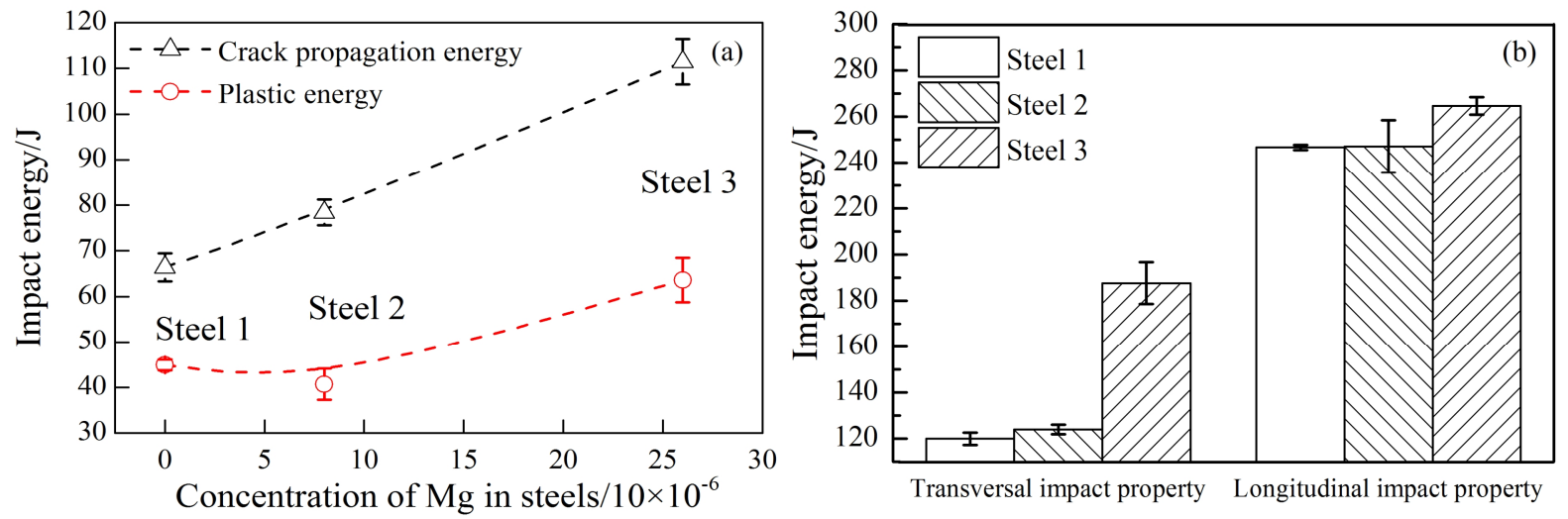

Figure 4 The impact energy of rolling state steels,(a) parameters of impact properties;(b)comparison crack propagation energy with plastic energy in the transversal impact properties

\section{Effect of Mg on Microstructure Characteristics}

Figure 5 shows the optical morphologies of the test steels. It is noted that the bonded structures are detected in the parallel to rolling direction both for steel 1 and steel 2, while the bonded structures are disappeared in steel 3. Moreover, the bonded structures are nearly disappeared in the microstructures perpendicular to rolling direction. Furthermore, compared with the steel 1, the ferrite grains are significantly refined with the concentrations from $0.0008 \%$ to $0.0026 \%$. Quantitatively, the ferrite grain average size is reduced from $9.69 \mu \mathrm{m}$ to $7.28 \mu \mathrm{m}$ and $4.31 \mu \mathrm{m}$ using linear intercept method, respectively. It suggests that the microstructure can be refined by the addition of $\mathrm{Mg}$ to the different extent. Based on the Hall-Petch relationship[12,13], the refinement of the ferrite grain size in Mg-containing steels could account for the increase in strength measured.

From the morphologies and products of view, for steel 1 , the microstructure is characterized by a mixture of polygonal ferrite, pearlite, and a little bainitic ferrite. For steel $2(0.0008 \% \mathrm{Mg})$, the amount of polygonal ferrite reduces, and the matrix phase is substantially bainite. When the concentration of $\mathrm{Mg}$ is $0.0026 \%$ (steel 3), the polygonal ferrite disappears, and the matrix phase is substantially bainite, of which a certain amount of acicular ferrite and granular bainitic ferrite are also detected. Considerable reports [14-18] have indicated that the bainite phase usually possesses high strength and good toughness for structural applications compared with the conventional ferrite-pearlite phase. Hence, the improved toughness and tensile of $\mathrm{Mg}$-containing steels are attributed to both the refined microstructure and the bainite dominated microstructure in steel.

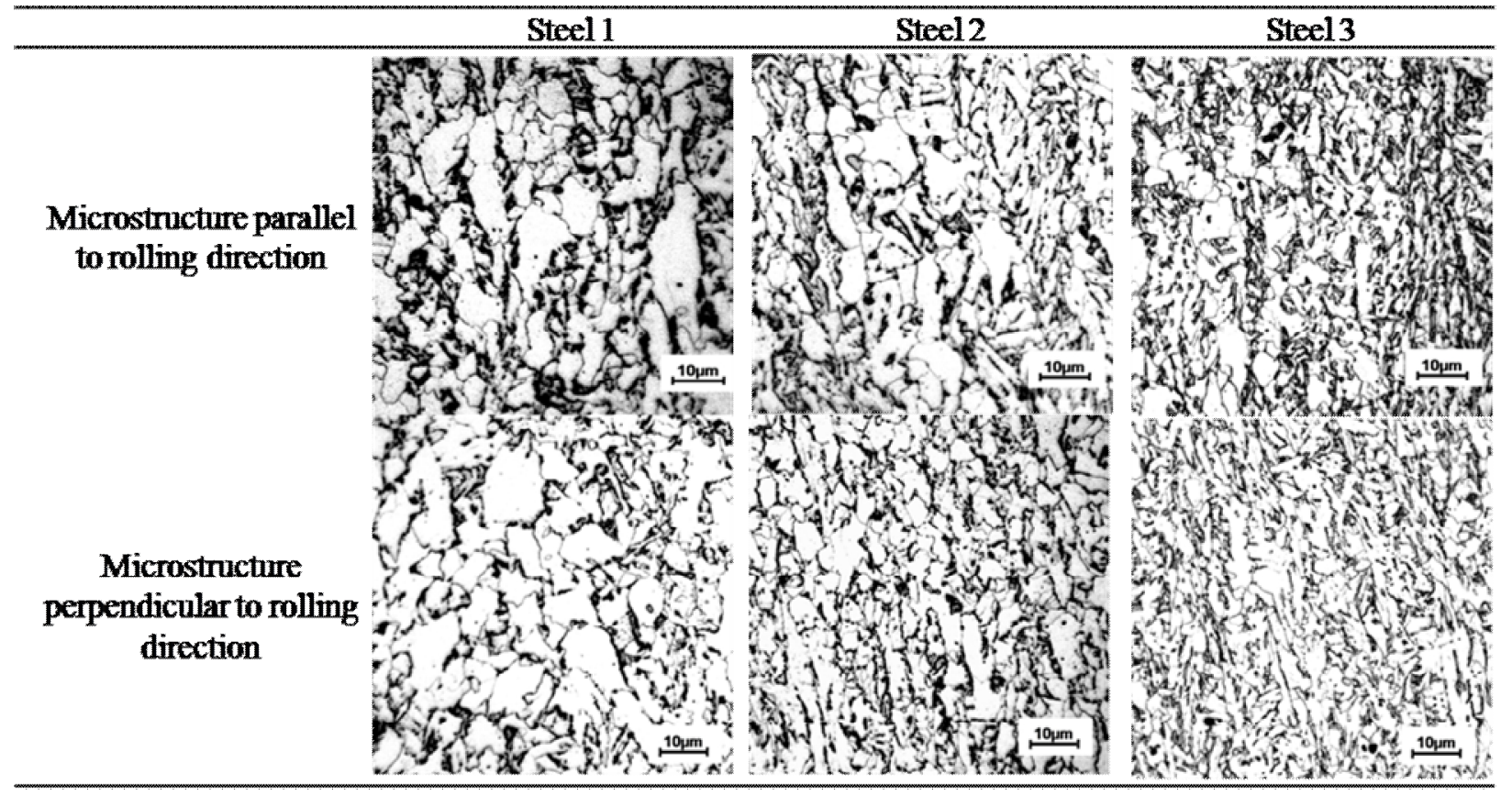

Figure 5 Optical micrographs of the rolled microstructure of steels 
Additionally, the tensile stress-strain curves of the steels demonstrate that the yield platform becomes to be insignificant after the content of $\mathrm{Mg}$ increase from $0.0008 \%$ to $0.0026 \%$. Ref. [19] proposed that the yield phenomenon of low carbon steel is mainly ascribed to the strong interaction between dislocations and solute atoms in mechanical properties. If the amount of bainite is high enough in microstructure, then the dislocation density would be high in the crystal, which could cause the strong interaction between dislocations and solute atoms being in the steel. Therefore, both the interaction among the dislocations and the strain hardening behavior is outstanding when a force exerted on the steel, thereby leading the insignificant yield platform in the tensile stress-strain curves. According to the microstructure characteristics of $\mathrm{Mg}$-containing steels, the bainite phase is obviously improved with $\mathrm{Mg}$ addition. Thus, the phenomenon that the yield platform of the $\mathrm{Mg}$ added-steels is not obvious may be related to the bainite structure.

\section{Summary}

The effect of trace Magnesium addition on the characteristics of mechanical properties in high strength low alloy steel has been investigated. The basic conclusions are the following:

(1) The yield and the tensile strengths increase with $\mathrm{Mg}$ content from $0.0008 \%$ to $0.0026 \%$. The $0.0026 \% \mathrm{Mg}$ addition makes the yield strength, tensile strength, and elongation of steel increase to $473 \mathrm{MPa}, 605 \mathrm{MPa}$ and $36.5 \%$, increasing by $38 \mathrm{MPa}, 70 \mathrm{MPa}$, and $8 \%$ compared with the steel without $\mathrm{Mg}$ addition.

(2)The improved toughness is obtained both the transversal and longitudinal impact, and the increment in the Charpy impact toughness is also characterized to increase with the concentrations from $0.0008 \%$ to $0.0026 \%$.

(3) The improved toughness and tensile of Mg-containing steels are attributed to both the refined microstructure and the bainite dominated microstructure in steel. Moreover, the bainitic structure obtained by the addition of $\mathrm{Mg}$ into the molten steel results in a continuous yield behavior emerges in $0.0026 \% \mathrm{Mg}$ steel.

\section{Acknowledgments}

The authors wish to thank the National Natural Science Foundation of China for providing financial support during this study (Project No. 51374059 and No. 51374060).

\section{References}

[1] J. Fu, Y. G. Yu, A. R. Wang, B. P. Chen, J. Mater. Sci. Technol. 14(1998)53-56.

[2] H. S. Kim, C. H. Chang, H. G. Lee, Scr. Mater. 53(2005)1253-1258.

[3] S. Kimura, K. Nakajima, S. Mizoguchi, Metall. Mater.Trans. B 32(2001)79-85.

[4] B. Wen, B. Song, N. Pan, Q. Y. Hu, J. H. Mao, Ironmak. Steelmak. 38(2011)577-683.

[5] A. Kojima, A. Kiyose, R. Uemori, M. Minagawa, M. Hoshino, T. Nakashima, K. Ishida, H. Yasui, Nippon Steel Technical Research, 90(2004)2-6.

[6] Isobe K, ISIJ Int. 50(2010)1972-1980.

[7] K. Kimura, S. Fukumoto, G. Shigesato, A. Takahashi, ISIJ Int. 2013,53(2013)2167-2175.

[8] J. Takamura, S. Mizoguchi, Proc. sixth int. iron and steel cong., Nagoya, ISIJ. (1990)591-597.

[9] F. Chai, C. F. Yang, H. Su, Y. Q. Zhang, Z. Xu, J. Iron and Steel Res. Int. 16(2009)69-74.

[10]K. Zhu, Z. G. Yang, J. Mater. Sci. Technol. 27(2011)252-256.

[11]A. A. Gorni, C. G. Cavalcanti, the 7th International Conference on Steel Rolling, Chiba, The Iron and Steel Institute of Japan, (1998)629.

[12]E. O. Hall, The deformation and ageing of mild steel: III discussion of results, Proc. Phys. Soc. B 64(1951)747-753.

[13]N. J. Petch, J. Iron Steel Inst. 174(1953)25-28.

[14]D. V. Edmonds, R. C. Cochrane, Metall.Trans.A 21(1990)1527-1540. 
[15]H. K. D. H. Bhadeshia, Mater. Sci. Forum, 284-286(1998)83-94.

[16]X. M. Wang, C. J. Shang, S. W. Yang, X. L. He, X. Y. Liu, Mater.Sci.Eng.A 438-440(2006)162-165.

[17]E. Choi, T. H. Nam, J. T. Oh, B. S. Cho, Mater. Sci. Eng. A 438-440(2006)1081-1084.

[18]I. A. Yakubtsov, P. Poruks, J. D. Boyd, Mater. Sci. Eng. A 480(2008)109-116.

[19] Y. M. Lin, Iron and Steel, 39(2004)51-54. 